\title{
Assessing small airways disease
}

\section{To the Editors:}

In their excellent study of the effect of small particle corticosteroids on small airway involvement in asthma, COHEN et al. [1], along with LAHZAMI and KING [2] in the accompanying lead editorial [2], decry the complexity associated with current measurements of small airways function. Those authors stress the desirability of finding simpler methods to assess small airways dysfunction.

A simple method of assessing smaller airways obstruction is easily available and could be used retrospectively. In contrast to the mean forced expiratory flow between 25 and $75 \%$ of forced vital capacity (FVC; FEF25-75\%), which measures the mid-portion of exhalation ending at nearly the same time as the forced expiratory volume in one second (FEV1) in these subjects, the $\mathrm{FEV} 3 / \mathrm{FVC} \%$ or $(1-\mathrm{FEV} 3 / \mathrm{FVC}) \%$ are excellent measures of small airways function. They measure the fraction of volume exhaled near the end of a forced exhalation, i.e. from airspaces and airways with the longest time constants [3, 4]. However, because they are ratios (as are FEV1/FVC and FEF25$75 \%$ ) they are not ideal measurements of airway responsiveness to bronchodilators. Rather, pre- and post-absolute volumes, such as FEV1, FEV3 and FEV6, should be compared to assess bronchodilator effect. Presumably, if there is a small airways bronchodilator effect in the ciclesonide-treated group, the increase from pre- to post FEV3 $(\triangle \mathrm{FEV} 3)$ or FEV6 $(\Delta \mathrm{FEV} 6)$ should exceed that of pre- to post-FEV1 $(\Delta \mathrm{FEV} 1)$. For example, if the $\triangle \mathrm{FEV} 1$ was $150 \mathrm{~mL}$ and the $\triangle \mathrm{FEV} 3$ and $\triangle \mathrm{FEV} 6$ were also $150 \mathrm{~mL}$, the dominant change was in the larger airways. If the $\triangle F E V 1$ was $150 \mathrm{~mL}$ and the $\triangle F \mathrm{FV}_{3}$ and $\triangle \mathrm{FEV} 6$ were 200 $250 \mathrm{~mL}$, there was also an important change in the smaller airways. These simple measurements would objectively disclose whether the smaller airways were directly affected by the ciclesonide.

It would be of interest and importance if COHEN et al. [1] and other authors would retrospectively or prospectively measure and report these findings to see whether these simple, quick and inexpensive measures are useful in evaluating drugs that modify small airways obstruction.

\section{J. Hansen}

Medicine, Harbor-UCLA Medical Center, Torrance, CA, USA.

\section{STATEMENT OF INTEREST}

None declared.

\section{REFERENCES}

1 Cohen J, Duoma WR, ten Hacken NHT, Vonk JM, Oudkerk M, Postma DS. Ciclesonide imporves measures of small airway involvement in asthma. Eur Respir J 2008; 31: 1213-1220.

2 Lahzami S, King GG. Targeting small airways in asthma: the new challenge of inhaled corticosteroid treatment. Eur Respir J 2008; 31: 1145-1147.
3 Hansen JE, Sun X-G, Wasserman K. Discriminating measures and normal values for expiratory obstruction. Chest 2006; 129: 369-377.

4 Hansen JE, Sun X-G, Wasserman K. Ethnic- and sex-free formulae for detection of airway obstruction. Am J Respir Crit Care Med 2006; 174: 493-498.

DOI: 10.1183/09031936.00088908

From the authors:

J. Hansen describes an interesting method for assessing small airways dysfunction, namely via the bronchodilator effects on forced expiratory volume in three seconds (FEV3) and FEV6, as compared with the effects on FEV1. As they are derived from flow-volume manoeuvres, these parameters are indeed simple to obtain, low-cost, show acceptable repeatability [1,2] and may reflect relevant changes in small airways obstruction. We therefore retrospectively analysed the FEV3 and FEV6 values and compared the treatment effects of ciclesonide on $\mathrm{FEV} 3$ and FEV6 to FEV1 in our study population [3]. To assess whether the changes in FEV1, FEV3, FEV6 and forced vital capacity (FVC) after treatment with ciclesonide were indicative of small airway changes, we correlated them with the changes in methacholineinduced air trapping on expiratory computed tomography scans, another method of assessing small airways function.

Table 1 demonstrates the changes after treatment in FEV1, FEV3, FEV6 and FVC. The ciclesonide-induced change in FEV6

\begin{tabular}{|c|c|c|c|}
\hline \multirow[t]{2}{*}{ TABLE 1} & \multicolumn{3}{|c|}{$\begin{array}{l}\text { Changes in forced expiratory volume in one } \\
\text { second (FEV1), FEV3, FEV6 and forced vital } \\
\text { capacity (FVC) after treatment with ciclesonide or } \\
\text { placebo }\end{array}$} \\
\hline & Ciclesonide & Placebo & $\mathrm{p}$-value \\
\hline \multicolumn{4}{|l|}{$\Delta \mathrm{FEV}_{1}$} \\
\hline$\%$ & $18.1(6.4-31.2)^{\#}$ & $-0.7(-1.9-8.6)$ & 0.003 \\
\hline $\mathrm{mL}$ & $550(263-825)$ & $-25(-67.5-205)$ & \\
\hline \multicolumn{4}{|l|}{$\Delta \mathrm{FEV}_{3}$} \\
\hline$\%$ & $11.8(7.9-14.6)^{\curvearrowleft}$ & $-0.3(-1.3-6.7)$ & 0.002 \\
\hline $\mathrm{mL}$ & $500(360-590)$ & $-15(-55-205)$ & \\
\hline \multicolumn{4}{|l|}{$\Delta \mathrm{FEV}_{6}$} \\
\hline$\%$ & $8.6(2.6-11.4)$ & $-0.9(-1.9-5.6)$ & 0.038 \\
\hline $\mathrm{mL}$ & $375(150-568)$ & $-40(-77.5-185)$ & \\
\hline \multicolumn{4}{|l|}{$\Delta \mathrm{FVC}$} \\
\hline$\%$ & $6.9(4.8-10.2)$ & $-1.2(-1.8-2.8)$ & 0.002 \\
\hline $\mathrm{mL}$ & $380(210-538)$ & $-55(-75-92.5)$ & \\
\hline $\begin{array}{l}\text { Data are pres } \\
\text { the ciclesonic } \\
\text { treatment diff } \\
\text { ciclesonide } \mathrm{d} \\
\#: \mathrm{p}<0.05 \text { ve }\end{array}$ & $\begin{array}{l}\text { ted as median (int } \\
\text { arm, three subjects } \\
\text { ences were tested } \\
\text { erences (\%) were } t \\
\text { us } \Delta \mathrm{FEV}, \Delta \mathrm{FEV} 6 \text { a }\end{array}$ & 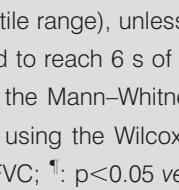 & $\begin{array}{l}\text { vise stated. In } \\
\text { on. Between- } \\
\text { st and within- } \\
\text { ned rank test. } \\
\text { FEV6. }\end{array}$ \\
\hline
\end{tabular}

